\title{
A ReSPONSABILIDADE do PODER JUDICIÁRIO FRENTE À POLÍTICA de INSERÇÃo DO DEFICIENTE NO MERCADO DE TRABALHO: O DIREITO CONSTITUCIONAL COMO PANO DE FUNDO PARA A IMPLEMENTAÇÃO DOS DIREITOS SOCIAIS
}

The responsibility of judicial sector in the process of inclusion of challenged people in the labour market: the constitutional law as background of implementation for social rights

Denise Morgado de Oliveira Junqueira

Mestranda em Direito Constitucional pelo Minter - ITE/CIESA. Pós-graduada em Direito do Trabalho. E-mail: denise.m.junqueira@gmail.com.

RECEBIDO EM: 22.10 .2013

APROVADO EM: 21.01.2013

\section{Resumo}

Realidade cotidiana em outros países, a inclusão do deficiente físico no Brasil encontra obstáculos, principalmente por ainda não fazer parte da nossa cultura. O Deficiente físico ${ }^{6}$ - entenda-se deficiente mental e físico - é considerado inválido, incapaz para assumir uma atividade laboral. O presente trabalho busca, entre as tentativas da iniciativa privada e do Poder Público de incluir o deficiente na sociedade, apontar a importância do Poder Judiciário, como protetor das Leis e dos Direitos Fundamentais, tendo por estrutura o Direito Constitucional e suas prerrogativas para a instauração do bem estar social. Para a efetivação e o alcance social das normas estabelecidas para a inclusão do deficiente físico é imprescindível uma mudança comportamental de todos e um maior empenho das autoridades, não só na criação, fiscalização e execução de normas, mas um comprometimento verdadeiro com a defesa do direito à igualdade, assim como do direito à vida, à liberdade e à dignidade.

Palavras-chave: Deficiente físico. Inclusão. Mercado de trabalho. Direitos CONSTITUCIONAIS.

\footnotetext{
${ }^{6}$ Nossas leis, mesmo depois de 5.10.1988, por vezes referem-se à deficiência física, embora a ela não pretendam restringir-se. Esse conceito é variado nas palavras, embora mantenha sua essência em várias constituições , na OIT e na ONU. Todos tratam como deficiente aquele ser humano que sofre limitação em grau considerável nas funções naturais do físico, da mente ou dos sentidos, para a realização das atividades do cotidiano.
} 


\title{
Abstract
}

Common sense in other countries, the inclusion of physically and mentally challenged people in the labour market in Brazil, isn't yet part of the culture. Among us, they consider challenged people not able to work. The aim of present work is to point out the importance of the role of the Judicial Sector, taking into consideration the attempts of Private and Public Sector.The Judicial Sector must be seen as a protector of fundamental rights, based on the structure of the Constitutional Law, and its prerogatives in the pursue of social welfare.

In fact, the effectiveness of social inclusion of challenged people implies a social and behavioral change, as well as, a deep commitment of the authorities. It is necessary to create, monitor and enforce the legal frame as a condition to ensure the right to life, to freedom, and to dignity.

Keywords: Poor Physical. Inclusion. Labour market. Constitutional Rights

\begin{abstract}
Sumário: Contextualização do problema: a dinâmica da sociedade em desenvolvimento e a proteção dos direitos das pessoas com defiência. 1. Breves considerações sobre os direitos constitucionais garantidos pela lei $\mathrm{n}^{\mathrm{0}} 7.853$, de 1989. 1.1. Reflexos da proteção legal à pessoa com deficiência. 1.2. Ações e medidas para inserção da pessoa com deficiência no mercado de trabalho a partir do judiciário. 1.2.1. As medidas extrajudiciais. 1.2.2. As medidas judiciais lato sensu. 1.2.3 Estado de direito: liberdade econômica, livre iniciativa e proteção do trabalhador: uma equação em desenvolvimento. Conclusão. Referências.
\end{abstract}

\section{ConteXTUAlizaÇão do PROBleMA: A DINÂMICA DA SOCIEDAdE EM DESENVOLVI- MENTO E A PROTEÇÃO DOS DIREITOS DAS PESSOAS COM DEFIÊNCIA}

Os seres humanos estão em constante evolução, e esta, varia de acordo com as necessidades e disponibilidades de tecnologia e conhecimentos, além da interação com o meio e entre si, o que amplia a gama de relações pelos interesses defendidos. Essa evolução individual ou de grupos é o dínamo propulsor da evolução das sociedades e essa dinâmica das mudanças sociais e individuais, por conseguinte, conclama os legisladores, juristas e a administração pública à busca de novas respostas às demandas daí advindas. Nas palavras de Alvino Lima: "A sociedade é a soma dos indivíduos juxtapostos, e a proteção da pessoa forma o conteúdo da noção e Direito." 7

\footnotetext{
${ }^{7}$ LIMA, Alvino. Da influência, no direito civil, do movimento socializador do direito. Revis-
} 
Não se pode perder de vista que, pela essência do ser social que condiciona o ser humano, a convivência é um imperativo natural, não tendo o homem condições de satisfazer cabalmente suas necessidades de maneira isolada. "Seu progresso moral, intelectual ou econômico, decorre da contínua aproximação a seus semelhantes." 8

"A sociedade se apresenta como um conjunto de relações entre indivíduos da espécie humana", portanto, sua evolução depende da evolução do indivíduo. O direito exerce um papel relevante enquanto criador, garantidor e manifestador dos direito individuais e coletivos.

No que se refere ao conceito de deficiente físico, na maioria dos casos é uma "definição cultural", onde a definição médica de alguma incapacidade física ou mental é apenas instrumental. A deficiência é delimitada pelos papéis, direitos, expectativas e o status social do deficiente e da comunidade onde convive, consistindo assim, num conceito social e flexível.

O conceito de deficiente legalmente admitido no Brasil é aquele estabelecido pelo art. $1^{\circ}$ da Convenção sobre o Direito das Pessoas com Deficiência, patrocinada pela Organização das Nações Unidas, convenção essa aprovada por Decreto Legislativo e promulgada pelo Presidente da República. ${ }^{10}$

Os deficientes - ou limitados em suas capacidades - receberam tratamento diverso ao longo da história, variando conforme a época e a localização, sendo que, na maior parte das vezes, este tratamento baseava-se em preconceitos, ignorância ou simplesmente baseado em crendices. Assim, os deficientes foram tratados como inúteis, dispensáveis, impregnados de maus desígnios, castigados por Deus - na visão de Santo Agostinho (anos 345 e 430), ou, seres doentes que poderiam corromper os sãos.

Alguns tratamentos especialmente cruéis foram dispensados aos deficientes ao longo da história: a) na Roma antiga, o patriarca tinha autorização legal, provinda da Lei das XII Tábuas, para matar seus filhos defeituosos; b) para os hebreus, a pessoa deficiente não podia dirigir os serviços religiosos; c) na Grécia, bastava que os recém-nascidos demonstrassem alguma fragilidade (não necessariamente apresentar uma deficiência), eram jogados num abismo com mais de dois mil e quatrocentos metros, chamado Taigesto; d) em pleno século XX, os nazistas sacrificavam pessoas deficientes para evitar que estes gerassem descendentes com os mesmos "defeitos".

ta Forense. Rio de Janeiro: Forense, out. 1939 - Apud MARQUES; MIRAGE, 2012, p, 26.

${ }^{8}$ ALARCÓN, Pietro de Jesús Lora. Ciência política, estado e direito público - Uma Introdução ao Direito Público da Contemporaneidade. São Paulo: Verbatim. 2011, p. 43.

${ }^{9}$ Ibidem., p. 46.

${ }^{10}$ Art. $1^{\circ}$ da Convenção da ONU sobre Direitos das Pessoas com Deficiência: Pessoas com deficiência são aquelas que têm impedimentos de longo prazo de natureza física, mental intelectual ou sensorial, os quais, em interação com diversas barreiras, podem obstruir sua participação plena e efetiva na sociedade em igualdade de condições com as demais pessoas. 
Por outro lado, pela influência de Aristóteles, em Atenas, os doentes e deficientes tinham acesso às atividades produtivas e exercícios, recebendo até mesmo algum auxílio, nos moldes da nossa Seguridade Social, quando não podiam realizar determinada atividade. Em Roma também se agiu assim. Temos outros exemplos de tratamento melhorado para os deficientes: a) A doutrina Cristã, na Idade Média, induziu os senhores feudais a amparar as pessoas deficientes; b) Na Inglaterra e na França, no século XIII, eram nomeados tutores e curadores para os doentes e deficientes; c) Nos fins dos séculos XIV e XV, com o Renascimento, o deficiente veio a ter reconhecida sua condição de humano, sendo que, a França, além de instituir a assistência social aos deficientes, passou a substituir gradativamente o assistencialismo pela integração do deficiente na área produtiva. ${ }^{11}$

As guerras fortaleceram a ideia de que os deficientes deveriam ser inseridos no processo de produção ou assistidos pela sociedade, devido ao grande número de pessoas vitimadas nos conflitos bélicos. Da mesma forma, a Revolução Industrial, causadora de diversas deficiências, também contribuiu para que maior atenção fosse dedicada à habilitação do deficiente para o trabalho. ${ }^{12}$

A proteção específica dos direitos das pessoas com deficiência somente veio a ser concretizada após a efetivação dos direitos sociais nas constituições modernas.

No Brasil, a proteção e garantias de direitos aos deficientes evoluíram de forma lenta e gradual nos últimos trinta e cinco anos, quando o legislador se ocupou em lhes garantir a dignidade e a sobrevivência. Em 1978, por força da EC n.12, estabeleceu-se a assistência social aos deficientes; em 1988, a CF consagrou diversos dispositivos aos deficientes; em 1989 foi criada a Política Nacional para a Integração da Pessoa Portadora de Deficiência, Lei n. 7.853, de 24 de outubro de 1989; em 1991, a Lei 8.2013 que dispõe sobre os Benefícios da Previdência Social, em seu art.93, criou a obrigatoriedade por parte das empresas de manter em seu quadro de empregados um número de pessoas que tenha alguma deficiência, proporcional ao número total de trabalhadores contratados e no $\S 1^{\circ}$ do dispositivo em questão, há a garantia de a estabilidade do empregado.

O Estado tem buscado através da criação de leis e projetos sociais integrar o indivíduo na sociedade, resgatando-lhe a dignidade e dando-lhe meios de provimento da saúde e bem estar. Mas ainda há muitos obstáculos a vencer até que se alcance o alvo desejado. Desde a aceitação da própria família do deficiente, passando pela preparação escolar, capacitação profissional, adequação do ambiente de trabalho - tanto estrutural como de pessoal, são exemplos gerais do que provoca a exclusão desse trabalhador.

Há que se considerar que ninguém é deficiente por opção e que qualquer

\footnotetext{
${ }^{11}$ NIESS, Luciana Toledo Távora; NIESS, Pedro Henrique Távora. Pessoas portadoras de deficiência no direito brasileiro. 1. ed. São Paulo: Juarez de Oliveira. 2003, ps. 5 e 6.

${ }^{12}$ NIESS e NIESS, Op. Cit., p. 7.
} 
pessoa pode se tornar deficiente, como nos casos de acidentes, guerras e doenças crônicas.

Por outro lado, a imposição legal de se contratar deficientes quando não se tem pessoas habilitadas em número suficiente para suprir as cotas exigidas, originando penalidades ao empregador, dá margem para ações nem sempre positivas, levando o empresário a forjar contratações, enquadrando antigos funcionários como deficientes ou contratando o deficiente, sem, no entanto, engajá-lo na atividade produtiva.

Mais do que efetivação da Lei, a integração do portador de deficiência no mercado de trabalho é exercício do direito à vida, à liberdade, à igualdade, à dignidade humana, Princípios Constitucionais norteadores de todo complexo legal brasileiro, que devemos perseguir e fazer valer através do conhecimento e prática.

A inclusão do deficiente deve deixar de ser compromisso social para se tornar necessidade empresarial, ou seja, mão de obra qualificada, imprescindível para o exercício da atividade empresarial, sem rótulos, sem dificuldades, sem segregação, para que, ao final, toda a sociedade saia ganhando.

Para tanto, necessárias são as ações do Direito e da Educação, atuando numa mudança cultural que há de extirpar o preconceito, tornando o sistema jurídico social e administrativo menos deficiente.

\section{BREves CONSIDERaÇões SOBRE OS DiREITOS CONSTITUCIONAIS GaRANTIDOS PELA LEI N $\mathbf{N}^{\circ}$ 7.853, DE 1989} cada"13.

Nos dizeres de José Afonso Silva: “Toda constituição é feita para ser apli-

A Carta Constitucional de uma nação é o principal instrumento de manifestação autêntica dos diversos interesses da sociedade, devendo se originar de uma reivindicação popular, num processo participativo e manter-se em permanente sintonia com as expectativas e necessidades do povo. Segundo Walter Claudius Rothenburg, "É preciso que verifique o apelo prático da Constituição, ou seja, que ela tenha condições de aplicar-se e seja efetivamente aplicada". Para essa efetividade, não basta o texto legal, é preciso a adesão popular do povo, com sentimento constitucional. ${ }^{14}$

A atual Carta Magna, de 1988, trouxe dispositivos garantidores de direitos e proteção aos deficientes de grande significância. Há que se considerar, antes de tratarmos dos efeitos das normas, as espécies e características das normas constitucionais, numa classificação especificamente constitucional. ${ }^{15}$

13 José Afonso da. Aplicabilidade das normas constitucionais. 8. Ed. São Paulo: Malheiros, 2012 p. 223.

${ }^{14}$ ROTHENBURG, Walter Claudius. Direito constitucional. 1. Ed. São Paulo: Verbatim. 2010 , p. 35.

${ }^{15}$ MENDES, Gilmar Ferreira et tal. Curso de direito constitucional. 2. Ed. São Paulo: Sarai- 
Chamamos, pela lógica, de normas constitucionais todas aquelas que se encontram na Constituição, surgindo daí a primeira característica dessas normas que é a dicotomia formal/material. Toda norma constitucional é formal, pois que inserida no texto da Carta Magna, e ainda materialmente formal pela essência de seu conteúdo. ${ }^{16}$

Quanto à sua executoriedade, a tradicional classificação chama de normas operativas aquelas que são dotadas de eficiência imediata, ou não dependem de condições institucionais ou de fato. Essas normas de aplicação imediata são caracterizadas por não deixar espaço entre o seu significado e o desencadeamento de seus efeitos, numa realidade normativa inelástica, insuscetível de modelagem. Essa norma não aceita limitação, entretanto, aceita regulamentação.

Noutra ordem, estão as normas programáticas que dependem de providências especificadas fora ou além do texto constitucional para a concretização de seus objetivos. São dispositivos constitucionais que, para adquirir plena eficácia jurídica, dependem de integração normativa, por meio de leis que "transmitam vida e energia a grande número de dispositivos" $" 17$, sendo elas, geralmente, com objetivos sociais.

Partindo, então, da eficácia e aplicabilidade da norma constitucional, essa pode ser considerada autoexecutável e não autoexecutável, sendo a primeira bastante em si, completa e suficientemente precisa na sua hipótese de incidência e na sua disposição. Seus efeitos são previstos no próprio dispositivo. Enquanto que a norma não aplicável é incompleta ou insuficiente, para cuja execução se faz indispensável a mediação do legislador, editando normas infraconstitucionais regulamentadoras.

Nesse passo, impende salientar que, no Brasil, a demora com a publicação de Lei regulamentar varia de quatro a vinte anos, período esse em que a norma só existe formalmente, sem qualquer aplicabilidade ou efeito.

Nessa esteira, para regulamentar os Direitos às pessoas deficientes, constantes no texto constitucional de 1988 , foi criada a Lei $\mathrm{n}^{0} 7.853 / 1989$, que por sua vez, foi regulamentada em 1999, pelo Decreto n. 3.298/99, atribuindo-lhe maior efetividade.

Dentre outras providências, a Lei n ${ }^{0} 7.853 / 1989$ atribui ao Ministério Público, de forma inédita, a defesa dos interesses difusos e coletivos da Pessoa Deficiente, tratando ainda de diversas matérias que se associam na construção de uma melhor qualidade de vida a essas pessoas.

Outro ponto que merece destaque é a criminalização (art. $8^{\circ}$ ) da conduta discriminatória ao deficiente, seja na escola, no trabalho, estabelecimento hospitalar ou mesmo no concurso público. Ainda disciplina a questão da acessibilidade, determinando normas para edificações públicas e particulares.

Aponta ainda a Lei $\mathrm{n}^{\mathrm{o}} 7.853 / 1898$, como valores básicos, a igualdade de

\footnotetext{
va. 2008 , p. 25.

${ }^{16}$ Ibidem., p. 28.

${ }^{17}$ SILVA, Op. Cit.,p. 224.
} 
tratamento e oportunidade, justiça social, respeito à dignidade da pessoa humana, bem-estar, e outros direitos constitucionais ou justificados pelos princípios gerais de direito. ${ }^{18}$

Os apontamentos de Luiz David Araujo, em sua obra publicada pela Secretaria de Estado dos Direitos Humanos do Ministério da Justiça, ${ }^{19}$ quando analisa os efeitos das normas constitucionais dos deficientes, indicam que o patrimônio jurídico do deficiente se resume no cumprimento do direito à igualdade, resguardando a obediência à isonomia de todos, evitando discriminações ou colocando os deficientes em posição privilegiada.

Os benefícios se justificam pela própria dificuldade de inclusão natural desse grupo de pessoas, devendo-se considerar, entretanto o dúplice enfoque do princípio da igualdade, previsto no art. $5^{\circ}$, que demonstra toda a preocupação do legislador constituinte de tratar as pessoas igualmente, sem qualquer distinção (igualdade formal ou igualdade perante a lei). Além disso, os valores realçados pela Lei Maior são direitos de pessoas ou grupos que necessitam de proteção especial em situações especificadas, caracterizando então, uma discriminação perfeitamente aceita e adequada à realidade vivida por tais grupos.

Resta claro que essa discriminação permitida se dá pela necessidade de desigualar, em busca da igualdade, não podendo o juiz, o administrador e o particular discriminar diante da aplicação da lei. Essa é a igualdade perante a lei, ou igualdade formal.

Em outro aspecto, devemos entender que a igualdade na lei nada mais é do que a proteção da cidadania e a dignidade da pessoa humana, eliminando as desigualdades sociais das pessoas deficientes, que, na sensibilidade do legislador depende de uma proteção específica para sua integração social. ${ }^{20}$

O sistema de proteção ao deficiente é formado por regras que discriminam, protegem, privilegiam, concede benefícios imprescindíveis aos olhos do constituinte, para a equiparação de certas situações ou grupos, dentre eles, o deficiente. Essa discriminação positiva não é inconstitucional desde que: a) a discriminação não atinja de modo atual e absoluto só um indivíduo; b) que o fator de desigualação consista num traço diferencial residente nas pessoas ou situações - vale dizer, que não lhes seja alheio; c) a existência de um nexo lógico entre o fator de discrímen e a discriminação legal estabelecida em razão dele; d) que no caso concreto, tal vínculo de correlação seja pertinente em função de interesses constitucionalmente protegidos, visando ao bem público. ${ }^{21}$

${ }_{18}$ GIL. Vilma Dias B. Pactos para inclusão das pessoas com deficiência no mercado de trabalho. Revista LTr, vol. 74, n.06, junho de 2010.

${ }_{19}$ ARAUJO, Luiz Alberto David. 4. Ed. A proteção constitucional das pessoas com deficiência. Brasília: Coordenaria Nacional para Integração da Pessoa Portadora de Deficiência. 1997, ps. 80.

${ }^{20}$ ARAUJO, Op. Cit. 1997, p. 84.

${ }^{21}$ BANDEIRA DE MELLO, Antônio Bandeira, citado por Geilson Salomão Leite. Disponí- 
Em resumo, a Lei 7.853/1989 dispõe sobre o apoio às pessoas portadoras de deficiência, sua integração social, e ainda previu a promulgação de outra lei para criar e assegurar reserva de mercado em toda a economia brasileira em favor da pessoa deficiente. Trouxe a aplicabilidade e efetividade às normas e preceitos constitucionais de direitos ao deficiente.

Em que pese o esforço normativo para diminuir a diferença entre deficiente e não deficiente na vida prática ainda temos muitos obstáculos a superar e novos hábitos a serem inseridos. As ações afirmativas, formas práticas da aplicabilidade legal como reserva de vagas e acessibilidade, enfrentam barreiras quase instransponíveis antes que surjam seus efeitos.

Como exemplo o que se deu com o direito à acessibilidade, que só foi garantido em 2000, com a Lei 10.098, mais de doze anos depois da promulgação da CF, sendo que os prazos ainda ficaram para o Decreto Regulamentar que demorou mais de quatro anos para ser feito, em patente descaso do Poder Legislativo.

O Poder Judiciário tem também sua mancha negra na história de defesa dos direitos do deficiente, afinal, demorou vinte e um anos para reconhecer às pessoas deficientes o direito de terem vagas reservadas no concurso da Magistratura!

\subsection{REFLEXOS DA PROTEÇÃo LEGAL À PESSOA COM DEFICIÊNCIA}

Sem sombra de dúvidas, a primeira consequência advinda da proteção legal do deficiente foi o reconhecimento de que são pessoas capazes, produtivas e úteis, garantindo-lhes os direitos básicos (direito à vida, dignidade, liberdade, saúde, educação, entre outros), mas também viabilizando meios para a sua inserção no mercado de trabalho e na sociedade.

Desde a Constituição de 1988, muitas normas tem sido criadas buscando efetivar esses direitos. Nesse ponto, deixando de lado os fatos, analisemos a doutrina jurídica no que se refere à contrafaticidade do direito.

Contrafaticidade significa que as normas jurídicas são contrárias aos fatos reais. Devemos entender que as normas possuem validade independente da lógica ou do senso comum. Tem o objetivo de determinar o dever ser que resulta em uma consequência jurídica que pode ser uma sanção ou um benefício. Esse caráter contrafático indica que a norma jurídica é sempre instrumento para a transformação social ou manutenção de princípios. Porém, a necessidade da imposição legal para que um objetivo seja atendido, assinala que a sociedade não está atenta a esses direitos ou aos seus destinatários.

Ao mesmo tempo em que o número grande de leis defensoras dos direitos do deficiente nos impressiona pelo cuidado do legislador em proteger, inserir na sociedade e garantir direitos fundamentais, também nos alerta para o fato de que o

vel em: http://www.projetoatbrasil.org.br/index.php?option=com_content\&view=article\&i$\mathrm{d}=16$ \&Itemid $=44$, Acessado em 05.09.2013. 
deficiente ainda vive discriminado ou invisível, prejudicado, marginalizado, necessitando assim de normas que modifiquem essa situação.

Mas há que se destacar como avanço dos direitos do deficiente como reflexo da proteção legal, com base na CF de 1988, da Convenção Internacional da ONU sobre os direitos da pessoa com deficiência, na legislação infraconstitucional dos Municípios, Estados e União os seguintes pontos ${ }^{22}$ :

a) O cidadão brasileiro com deficiência poderá tomar medidas administrativas, junto ao Estado, nas três esferas Governamentais, e poderá ajuizar ações judiciais, bem como medidas judiciais perante o Poder Judiciário, respeitadas as normas processuais de competência, em todas as instâncias para garantir os seus direitos e para obter recursos para a prevenção e tratamento das doenças que o acometem;

b) Reconhecimento do Poder Judiciário e as Instituições indispensáveis à administração da justiça, como o Ministério Público e as Defensorias Públicas - art. 13 da Convenção da ONU sobre pessoas com deficiência e o acesso à Justiça;

c) Assistência jurídica gratuita;

d) Prioridade no andamento dos processos judiciais e procedimentos administrativos;

e) Direito ao trabalho e da não discriminação (art. 37, VII da CF/ Lei 8.112/90 e Lei 8.2013/91, art. 93;

f) Liberdade de escolha do trabalho e em igual oportunidade, em ambiente inclusivo e acessível (decorre dos princípios inerentes à dignidade da pessoa, à autonomia individual, à liberdade de fazer as suas próprias escolhas e à independência que se almeja);

g) Direito à informação, art. $5^{\circ}$, XXXIV da CF. Abarca todas as informações sobre o diagnóstico, tratamento, prognóstico. Todavia, não se restringe apenas à qualidade da informação, mas também o direito a que essas informações lhe sejam transmitidas de forma mais adequada possível, por profissionais capacitados, de modo a não agravar o estado psicológico do deficiente;

h) Benefício de prestação continuada da Assistência Social - art. 203, V da $\mathrm{CF}$ / Lei 8.742/1993. Garante o recebimento de um valor mensal equivalente a um salário mínimo à pessoa deficiente ou ao idoso, desde que comprovado que não possuem meios para prover a própria manutenção, ou de tê-la provida por sua família, independentemente de contribuição para a Previdência Social;

i) Isenções Tributárias para as pessoas com deficiência - Sistema Tributá-

${ }^{22}$ Projeto AT/Brasil. AT - Proteção Legal Brasileira e Direito das Pessoas. Proteção Legal Brasileira e Direitos da Pessoa com Deficiência. 
rio Brasileiro, art.s 145 a 156, disciplinando matérias alusivas à competência tributária, normas - princípio, direitos fundamentais do contribuinte, imunidades, normas gerais e tipologia tributária. O Princípio da Igualdade Tributária está expresso no art. 150, II da CF;

j) Isenção fiscal do imposto sobre operações financeiras - IOF para os deficientes - incide sobre operações de crédito, câmbio e seguro e títulos ou valores mobiliários;

k) Isenção às pessoas com deficiência sobre a renda - IRPF. Art. 153, II da CF, o IRPF está submetido aos princípios da generalidade, universalidade e progressividade, sendo regido pelas Leis n. 7.713/88 e 9.205/95 e regulamentado pelo Decreto n. 3000/99;

1) Saque do FGTS - tanto de todo o saldo da conta, como das quantias depositadas mensalmente pelo empregador do pai ou mãe, para tratamento de dependente (art. 20, Lei 8.036/90);

m) Assistência Farmacêutica desenvolvida pelo Ministério da Saúde- direcionada a aquisição de medicamentos da atenção básica à saúde;

n) Serviço Humanitário de Transporte de medicamentos importados.

Apesar de que ainda há muito a se fazer, principalmente na estruturação física de acessibilidade, tratamentos médicos, qualificação profissional do deficiente e educação da população, as normas em vigor orientam esse procedimento de reconhecimento de direitos, institucionaliza políticas públicas e mais, pelo caráter pedagógico tenta adequar o pensamento e a cultura popular para diminuir a diferença entre deficiente e não deficiente.

\subsection{AÇões E MEdidas PARA INSERÇão da PESSOA COM DEFICIÊNCIA NO MERCADO DE TRABALHO A PARTIR DO JUDICIÁRIO}

A atividade laboral, de importância social, política e econômica é normatizada pela Consolidação das Leis Trabalhistas, a CLT, de 1943. Constitui mais que fonte de sustento, eis que provedora da dignidade, independência e bem estar do indivíduo e geradora de riquezas, bens e serviços para a coletividade.

O direito do trabalho nas Constituições é um ramo com princípios e normas próprias, tendo como objeto disciplinar o trabalho profissional, suas garantias consideradas fundamentais, as regras de organização e os direitos e deveres básicos que devem ordenar as relações de trabalho. A valoração que se desenvolve no plano Constitucional do direito trabalhista se dá em três ordens: a do trabalho, a dos direitos sociais e a dos direitos trabalhistas. ${ }^{23}$

Para a Constituição da China (1982, art.42), o trabalho é um "honroso

\footnotetext{
${ }^{23}$ NASCIMENTO, Amauri Mascaro. CURSO DE DIREITO DO TRABALHO. $20^{\mathrm{a}}$ ed. São Paulo: Saraiva. 2005, ps. 190 a 193.
} 
dever de todos os cidadãos aptos a fazê-lo". Proclama a Espanha (1978, art.35) que "todos os espanhóis tem o dever de trabalho e o direito ao trabalho, à livre escolha da profissão e ofício, à promoção por meio do trabalho e a uma remuneração suficiente para satisfazer suas necessidades e as de sua família". Preceitos similares expressam as Constituições do Japão (1946, art. 27), de Portugal (1976, art. 59) e de Cuba, (1976, art.44), para a qual p trabalho "é um direito, um dever e um motivo de honra para o cidadão".

A Constituição brasileira (1988) declara o trabalho como um dos princípios gerais da atividade econômica, a partir da valorização do trabalho humano e da livre iniciativa (art. 170) e a busca do pleno emprego (art. 170, VIII). Os direitos e garantias fundamentais estão dispostos no art.5 $5^{\circ}$ XII e no art. $7^{\circ}$.

Segundo Amauri Mascaro, a valorização do trabalho no Brasil, até atingir o nível constitucional, percorreu um longo caminho.

A proteção ao deficiente se concentrava em algumas normas coletivas que tratavam de garantia de emprego ao acidentado.

Em 1978, a EC. N. 12 estabeleceu em um único artigo que os deficientes não poderiam ser discriminados quanto à admissão ao trabalho ou ao serviço público e a salários - inciso III.

A Lei n. 7.853/89 instituiu a Coordenadoria Nacional para a Integração das Pessoas Portadoras de Deficiência (CORDE).

A CF de 1988 inovou quanto à situação jurídica do trabalhador portador de deficiência, ao estabelecer no art. $7^{\circ}$, XXXI a proibição de qualquer tipo de discriminação, principalmente no tocante a salário e critérios de admissão ao trabalhador deficiente, propiciando importantes avanços no que toca à proteção deste. Convém destacar que na Subcomissão dos Direitos dos Trabalhadores, na Comissão de Ordem Social e na Comissão de Sistematização da Assembleia Constituinte, não havia texto sobre o tema. ${ }^{24}$

A partir da Convenção n. 159 da OIT, foi criada a política nacional sobre reabilitação profissional no emprego das pessoas deficientes, com a finalidade de inseri-las no mercado regular de trabalho o Decreto Legislativo n.51 de 25 de agosto de 1989 e promulgada pelo Decreto n. 129 de 22 de maio de 1991.

A legislação previdenciária agregou restrição indireta à dispensa de empregados portadores de necessidades especiais, estipulando que o obreiro submetido a processo de reabilitação profissional somente poderia ser dispensado mediante a correlata contratação de outro trabalhador em situação semelhante (art. 93, $\S 1^{\circ}$, Lei n. $8.213 / 91) .{ }^{25}$

A garantia de vagas de emprego para pessoas com deficiência no Brasil está amparado pela Lei 8.213/91, conhecida como lei de cotas. Esta lei obriga as

\footnotetext{
${ }^{24}$ MARTINS, Sérgio Pinto. Direito do trabalho. 22. ed. São Paulo: Atlas. 2006, p. 471.

${ }^{25}$ DELGADO, Mauricio Godinho. Curso de direito do trabalho. 8. ed. São Paulo: LTr. 2009, p. 733.
} 
empresas com 100 ou mais empregados a reservarem vagas para pessoas deficientes, em proporções que variam de acordo com o número de empregados: de 100 a 200, reserva $2 \%$; de 201 a 500 , de $3 \%$; de 501 a 1.000 , reserva de $4 \%$; acima de 1.001 , $5 \%$ das vagas devem ser reservadas às pessoas deficientes. O Estado retirou de suas costas esse dever, transferindo-o para a iniciativa privada. As empresas que descumprirem tal regramento legal estarão sujeitas a lavratura de autos de infração pela fiscalização das Superintendências Regionais do Ministério do Trabalho e Emprego ou ajuizamento de Ação Civil Pública pelo MTE.

Essa lei vigora há mais de 20 anos, e o Ministério do Trabalho e do Emprego, em suas fiscalizações se deparam com o seu descumprimento, justificando as empresas a falta de mão de obra qualificada. Tarefa de difícil avaliação, a qualificação das pessoas para o trabalho, torna-se quase impossível se esse trabalhador estiver fora do mercado de trabalho, até mesmo porque a qualificação e avaliação de um trabalhador ocorre ao longo do exercício das atividades que realiza dentro da empresa, somando-se o treinamento que o trabalhador recebe no próprio local de trabalho.

\subsubsection{As medidas extrajudiciais}

As medidas extrajudiciais para inserção da pessoa deficiente no mercado de trabalho se dão tanto na esfera da administração pública, quanto da empresa privada, Organizações não governamentais, Fundações abrangendo a Educação e a Saúde.

A sociedade atual tem como característica a produção e consumo em alta escala. Isso requisita mão de obra qualificada e competente para o exercício da atividade laborais. O obreiro deve ser treinado, conseguir um bom desempenho em sua vida escolar, além de se especializar na sua área de atuação.

Nota-se que, por exigência do mercado, um emprego que atenda às necessidades do trabalhador está cada vez mais concorrido quando se trata da pessoa sem deficiência. Imagine só as barreiras encontradas pelo deficiente para se empregar e se manter empregado.

Dessa feita, a empresa privada e a Administração Pública tem criado, juntas ou separadamente políticas de inserção do deficiente no mercado de trabalho.

A Convenção da Pessoa com Deficiência visando providenciar mecanismos estruturais de educação e profissional para a pessoa com deficiência, em obediência ao art. 27, alíneas “d”e "j"da CDPD passou essa incumbência ao Estado para a promoção de oportunidades aos deficientes para o trabalho, empreendedorismo e cooperativas, destacando-se o acesso aos programas de orientação técnica e profissional, serviços de colocação no trabalho e treinamento profissional e continuado; apoio para a procura, obtenção e manutenção do emprego.

O Governo Federal instituiu por meio do Decreto n,7.612 de novembro de 2011 o Plano Nacional dos Direitos da Pessoa com Deficiência- PLANO VIVER 
SEM LIMITE, a ser executado pela União, projeto capitaneado pela Secretaria Nacional de Promoção dos Direitos da Pessoa com Deficiência cujas ações atendem aos pedidos da Conferência Nacional, podendo contar com a participação popular, que por sua vez é muito importante, já que traduz com mais precisão quais são as necessidades do segmento e seus anseios. Essa participação é algo que faz a diferença no presente e fará no futuro, eis que as novas gerações encontrarão cidades mais acessíveis e direitos consolidados.

O Plano Viver sem Limite tratou de instituir formas práticas para viabilizar o acesso à justiça por parte da pessoa com deficiência, adequando as dependências e prédios onde funcionem os serviços do sistema de justiça, como Fóruns, Defensorias, Promotorias e Delegacias. O acesso à justiça também deverá ser assegurado inclusive quanto às ações processuais. Nosso Código de Processo Civil em vigor trata da presença do intérprete para traduzir linguagem mímica - LIBRAS - dos surdos mudos, no art. 151 III, do CPC. Entretanto, não há capacitação de funcionários da justiça ou de Magistrados, nem do Órgão Ministerial, nesse ponto.

No ano de 2012, o Plano Nacional dos Direitos da Pessoa com Deficiência - Viver sem Limite, publicou um balanço das atividades exercidas no primeiro semestre, sendo que, a maioria delas com metas atingidas ${ }^{26}$, interagindo com programas de outros setores, dividindo essas ações em Eixos, tais como PRONATEC- Programa Nacional de Acesso ao Ensino Técnico e Emprego, no Eixo Educação- disponibilizou vinte mil vagas para pessoas deficientes; entregou 678 ônibus escolares a 519 municípios; licitou 13.500 novas salas de recursos multifuncionais; selecionou 2.866 municípios que serão beneficiados com 10.000 Escolas Acessíveis.

No Eixo Acessibilidade, o programa de habitação Minha Casa, Minha Vida contratou 99.185 moradias adaptáveis; foi lançado o microcrédito que é uma linha de crédito do Banco do Brasil; foi inaugurada uma unidade do Centro de Tecnologia da Informação (CTI) Renato Archer ${ }^{27}$, em Campinas, incluindo a habilitação 29 Núcleos Interdisciplinares de Inovação em Tecnologia Assistida, capaz de atender demandas tecnológicas das indústrias voltadas para o tema inclusão do deficiente; início do primeiro centro tecnológico de treinamento para Cães-Guia.

No âmbito tributário, ficaram desonerados de COFINS e PIS os produtos de tecnologia assistiva por meio da Lei n.12.649/2012; lançamento do catálogo nacional de produtos de tecnologia assistiva (www.assistiva.mct.gov.br).

Ainda como ações do Viver sem limite, destacamos o Eixo Saúde onde houve pactuação com o Centro de Referência em Reabilitação - CER, com a aprovação da Rede de Cuidado à Pessoa com Deficiência, via portaria n.793. Foram apro-

\footnotetext{
${ }^{26}$ Secreteria Nacional de Promoção dos Direitos da Pessoa com Deficiência. Disponível em: http://www.pessoacomdeficiencia.gov.br/app/viver-sem-limite/balanco-do-plano-agosto-de-2012. Acessado em 06.09.2013.

${ }^{27}$ Centro de Tecnologia da Informação Renato Archer. Disponível em http://www.cti.gov.br/. Acessado em 06.09.2013.
} 
vadas três oficinas ortopédicas para a região Nordeste (Cuité/PB, Juazeiro do Norte/ $\mathrm{CE}$ e Aracaju/SE); foram instituídos grupos de trabalho para publicação de diretrizes de ações de acessibilidade.

Por fim, alterações da legislação passaram a permitir a suspensão do Benefício de Prestação Continuada de Assistência Social - BPC, na ocasião da contratação trabalhista do beneficiário e retorno automático após a saída do emprego, além do acúmulo do benefício com a renda do aprendiz. (Lei n.12.470/2011).

Nesse tópico vale destacar a acumulação da Aprendizagem (Lei n. 10.097/200) e Benefício da Prestação Continuada, complementada pela Lei $11.180 / 2005$ e art.428, $\S 5^{\circ}$ e $6^{\circ}$ da CLT. Essas normas são importantes para o contrato de aprendizagem da pessoa com deficiência, a que se junta à concessão de benefício da prestação continuada, sem a consideração da idade máxima de 24 anos para o termo final do contrato de aprendizagem.

Soma-se a essa iniciativa federal a criação de Grupos de Trabalho com o objetivo de promover ações referentes à acessibilidade e capacitação do trabalhador deficiente.

Dessa forma, a empresa privada colabora em muitos sentidos:

a) Obedecendo à lei das cotas e até mesmo ultrapassando o número estipulado;

b) Qualificando o empregado deficiente;

c) Proporcionando um ambiente de trabalho hígido e adaptado para as suas condições;

d) Criação de espaços para sensibilização e conscientização das lideranças sobre o compromisso de cumprir o programa estabelecido;

e) Firmando parcerias com institutos que podem orientar, como o SESI (Serviço Social da Indústria);

f) Realização de treinamento para lideranças e pessoa de recursos humanos como, por exemplo, curso de libras;

g) Comprometimento da empresa e dos integrantes dessa para que a inclusão seja estabelecida respeitando a singularidade das deficiências e da personalidade de cada empregador.

\subsubsection{As medidas Judiciais lato sensu}

No papel, as intenções de acessibilidade e inclusão do deficiente estão mais próximas de serem materializadas, seja pela criação de normas (leis, decretos, portarias), políticas públicas ou ações da empresa privada.

No entanto, nem é necessária a realização de uma perícia, bastando provas testemunhais para concluirmos a inexistência dos acessos determinados pela Lei, não foram realizados a adaptação e os ajustes necessários, embora os generosos prazos concedidos. 
No Polo Industrial de Manaus, onde se concentram indústrias de grande e pequeno porte, fabricando e comercializando vários tipos de produtos, ainda se vislumbra situações vexatórias para a sociedade. Numa dessas fábricas, numa visita de acadêmicos de direito, um dos diretores se vangloriava dos equipamentos de última linha, enquanto que, perguntado pelas rampas de acesso, número de deficientes na linha de produção e da adequação estrutural do prédio para acolhimento dos deficientes, simplesmente respondeu que era "problema do RH", e que tinham um banheiro para deficientes no primeiro galpão, entre os quatro existentes.

Há também notícias de uma empresa nacionalmente conhecida na fabricação de eletroeletrônicos que chegou a adaptar estações de trabalho inteiras, somando mais de 70 empregados deficientes na linha de produção, incluídos em meio aos demais empregados, mas que, infelizmente está com seu projeto suspenso em razão dos demais empregados que, sentindo "rebaixados" por estarem em meio aos deficientes, começaram a constranger e humilhar os colegas especiais.

Infelizmente, nessas situações em que o descaso, a discriminação acontecem, não por falta de informação e conhecimento, mas por livre arbítrio dos gestores e demais membros da instituição, faz-se necessário o uso de um dos braços que sustentam a sociedade, qual seja, usar os meios judiciais para resolver a questão, amparado nas leis, na moral e nas propostas de desenvolvimento humano.

Diante do grande número de pessoas deficientes que precisam ser atendidas, "do berço ao túmulo", a justiça disponibiliza alguns instrumentos processuais, intergrados com todas as áreas do direito.

As ações podem ser propostas em todos os juízos de acordo com sua competência em razão da matéria, respeitados os limites de custas, em todas as instâncias e nas áreas Federal, Estadual, Trabalhista ou Juizado Especial, Cível ou Criminal. Essa possibilidade de defesa de direitos dos deficientes se estende até mesmo à pessoa que não tenha qualquer deficiência, mas que busca defender os direitos desses, valendo-se de representação perante os poderes públicos, garantido pela Constituição Federal.

Não se trata de rol taxativo, mas relatamos a seguir, alguns desses instrumentos de quais podemos fazer uso para a defesa dos direitos dos deficientes. São medidas que podem ser executadas com ou sem advogado; voltadas ou não para uma indenização pessoal; dirigida ou não como uma forma de correção da omissão do Poder Público. "É o exercício da cidadania pura e simples."28

a) Uma das formas mais simples, que sequer exige a presença de advogado, sem maiores formalidades, não significando que não seja eficiente, é a REPRESENTAÇÃO AO MINISTÉRIO PÚBLICO. O cidadão, deficiente ou não, pleiteando ou não indenização, denuncia as irregularidades aos Poderes Públicos competentes, no caso ao Ministério Público. O denunciante

${ }^{28}$ ARAUJO, Op. Cit.2011, p. 40. 
se torna apenas o agente iniciador do processo, entretanto, não terá qualquer controle sobre o andamento do processo, dependendo da concepção e atitude do Ministério Público, o dono da ação ou advogado do denunciante na causa.

b) Quando a necessidade é de uma providência básica e a pessoa interessada não queira denunciar ninguém, apenas solicitar que se cumpra o dever constitucional de tornar acessível o bem, pode-se fazer uso da REPRESENTAÇÃO AO PODER PÚBLICO para que tome a providência, ressaltando a denúncia ao Ministério Público em caso de descumprimento. Incumbe ao solicitante demonstrar a responsabilidade dos agentes e o potencial de seu pleito.

c) Importantíssimo instrumento processual, a AÇÃO PUPULAR, infelizmente pouco usada, é também um eficiente meio de se defender os direitos dos deficientes. Apesar da exigência de um advogado, pode ser ajuizada por qualquer cidadão, ou seja, um indivíduo que esteja com seus direitos políticos em ordem.

O objetivo da Ação Civil Pública, que pode ser preventiva, regulamentada pela Lei 4.717 de 1965, é o restabelecimento da situação, condenando os agentes públicos e os beneficiários do ato ilegal ao pagamento dos prejuízos causados. Por essa via, "a coisa pública é ressarcida não pelo dinheiro público, mas pelo dinheiro dos agentes públicos que forma negligentes ou omissos." 29

d) As ações acima elencadas tem a característica de não visar um bem pessoal, intencionando providências que promovam o bem estar geral, buscando funcionar a Administração Pública para que esta, por si mesma repare as questões danosas. Noutra ponta, o ajuizamento de AÇÃO NO JUIZADO ESPECIAL, tanto com ou sem advogado, é uma providência para quem busca um direito próprio, a compensação, o ressarcimento de um dano sofrido causado pela Administração Pública ou por um particular. Esses prejuízos devem ser comprovados e a sua indenização deve ser vista como uma ação mais do que legítima. As ações no Juizado Especial, Cível ou Criminal está ordenada pela Lei 9.099/1995. Comporta pedidos de indenização por danos morais e danos materiais.

e) O MANDADO DE SEGURANÇA é também muito eficaz na defesa dos direitos dos deficientes. Ação que detém características próprias serve para resguardar direito líquido e certo diante de violação ou ameaça a direito por autoridade pública, que não seja amparado por Habeas Corpus ou Habeas Data. Tem natureza de remédio constitucional, de natureza mandamental, ritos sumário e especial. Fundamentado constitucionalmente no art. $5^{\circ}$, incisos LXIX e LXX, o Mandado de Segurança comporta pedido

${ }^{29}$ ARAUJO, Op. Cit., 2011, p. 55. 
de liminar e pode ser ajuizado em defesa de direitos próprios ou coletivos. $\mathrm{Na}$ defesa dos direitos dos deficientes, esse remédio processual é usado principalmente como garantidor de cotas para universidades, trabalho e cursos profissionalizantes e compra de bens com isenção de IPI.

Do Mandado de Segurança 13/2011, o STJ sumulou decisão, Súmula 377³0, que reconhece que a visão monocular constitui motivo suficiente para reconhecer direito líquido e certo do candidato à nomeação e posse no cargo público pretendido entre as vagas reservadas aos portadores de deficiência física.

O cidadão que necessitar de ordem judicial, em caráter de urgência para preservar ou decretar um direito, tem como instrumento as MEDIDAS LIMINARES, que podem ser ajuizadas separadamente ou em conjunto com a ação principal. Seu objetivo primeiro é a concessão de tutela de urgência, antecipando os efeitos no todo ou em parte.

É o pedido adequado quando da necessidade de aplicação de medidas legais em defesa dos deficientes, como, por exemplo, para medida protetiva de abrigamento de deficiente.

Temos ainda a tutela penal da pessoa com deficiência. O Código Penal contempla a proteção da pessoa com deficiência, sob duas formas de tutela: a proteção da pessoa com deficiência que pratica a infração pena e a proteção do deficiente que é vítima do delito, condição que pode majorar a pena.

Analisado o caso concreto e detectado um dano, seja moral ou material, o detentor do direito deve acionar a justiça, interpondo ação de indenização por danos sofridos pela omissão ou ação do agente público ou particular que não tenha atendido às determinações legais de proteção ao deficiente.

Porém, ao contrário do que tem sido visto na prática, a ação de indenização não deve ser vista como um meio de enriquecimento. Algumas pessoas, ao se verem em situação de risco, mas em condições de evitar o mal maior, ficam inertes, percebendo todo o prejuízo, vislumbrando, na ocasião, uma possibilidade de pleitear uma gorda indenização.

A natureza da ação indenizatória deixa claro seu objeto: indenizar, ressarcir, recompor, recompensar um mal causado por uma ação ilícita. Portanto, mais do que justo que se busque o ressarcimento e, mais que louvável, tomar as iniciativas necessárias e possíveis para se evitar o prejuízo.

${ }^{30}$ Súmula 377 - STJ. Órgão Julgador: S3 - Terceira Seção; Data do Julgamento: 22.04.2009; Data de Publicação; 05.05.2010. Enunciado: O portador de visão monocular tem direito de concorrer, em consurso público, às vagas reservadas aos deficientes. 


\subsubsection{Estado de direito: Liberdade Econômica, livre iniciativa e proteção do trabalhador: uma equação em desenvolvimento}

O Estado de direito é uma situação jurídica, ou sistema institucional que submete cada um ao respeito do direito do outro, do simples indivíduo até a potência pública.

A constituição prevê como pressuposto para o estado democrático a Liberdade Econômica, que significa estar livre para negociar, liberdade para dispor dos recursos de que dispõem, seja mercadoria, bens de produção ou capital. Significa também liberdade para contratar ou demitir empregados e se demitir desde que não viole a legislação trabalhista.

O princípio da Livre Iniciativa é considerado com o fundamento da ordem econômica e atribui à iniciativa privada o papel primordial na produção ou circulação de bens ou serviços. É a base sobre a qual se constrói a ordem econômica.

Buscar o equilíbrio social, de forma justa e legal, numa balança em que serão expostas a liberdade econômica, a livre iniciativa e a proteção ao trabalhador, já é uma trabalhosa equação. Quando se trata do trabalhador deficiente, essa tarefa torna-se mais desafiadora.

No seu papel de fiscalizador, incentivador e planejador, o Estado tem desempenhado muito mais a função de fiscalizador, penalizando, suspendendo projetos da iniciativa privada do que incentivando e planejando.

As soluções apresentadas são, quando da parte pública, importadas. Não se tem programas, sequer experimentais, de adequação das necessidades do mercado com a capacidade do trabalhador.

Não se ouve falar em incentivos de qualquer espécie que estimulem às empresas ao cumprimento da lei de cotas, sendo, muitas vezes financeiramente mais viável o pagamento de multas do que a implantação de setores de treinamento.

Esse equilíbrio depende da atuação do Poder Judiciário para a aplicação das leis, do executivo proporcionando soluções e da população de onde deve emanar a vontade maior de realização. No caso, desejo de diminuir as desigualdades.

\section{Conclusões}

A lei tem concedido às condições possíveis na busca da defesa dos direitos dos deficientes. Os meios processuais, assim como a declaração desses direitos estão estampados por todo o sistema normativo.

Mas isso não é tudo. Até que a pessoa deficiente receba um tratamento igualitário, minimizando as dificuldades geradas por sua deficiência, seja física ou mental, ainda há muito o que se fazer.

$\mathrm{Na}$ seara do direito, se espera decisões mais rápidas e equilibradas, que atendam não somente ao indivíduo, mas que também sirvam a toda comunidade. O 
Judiciário desempenha importante papel coibindo e punindo a discriminação, mas falta o incentivo, o estímulo para as ações positivas.

Falta ainda o comprometimento social, a coesão em torno da causa do deficiente. Desenvolvimento de tecnologias que facilitem a execução de tarefas laborais, melhorias no transporte público. Práticas médicas atualizadas e acessíveis, assim como tratamentos alternativos e preventivos ao alcance de todos, feita por profissionais especializados, como fisioterapeutas, psicólogos, professores, fonoaudiólogos, preparadores físicos.

A Constituição formal está posta a todos. Cabe aos destinatários das normas dar-lhes o cumprimento. Cabe aos cidadãos a defesa de seus direitos e de seus iguais, ainda que tenham entre si, algumas diferenças.

\section{REFERÊNCIAS}

ARAUJO, Luiz Alberto David. Barrados - pessoas com deficiência sem acessibilidade: como, o que e de quem cobrar. 1. ed. Petrópolis: KBR. 2011.

ARAUJO, Luiz Alberto David. 4. ed. A proteção constitucional das pessoas com deficiência. Brasília: Coordenaria Nacional para Integração da Pessoa Portadora de Deficiência. 1997.

BANDEIRA DE MELLO, Antônio Bandeira, citado por Geilson Salomão Leite. Disponível em: http:/www.projetoatbrasil.org.br/index.php?option=com_content\&view $=$ article\&id=16\&Itemid=44. Acessado em 05.09.2013.

DELGADO, Mauricio Godinho. Curso de direito do trabalho. 8. ed. São Paulo: LTr. 2009.

GIL. Vilma Dias B. Pactos para inclusão das pessoas com deficiência no mercado de trabalho. Revista LTr, vol. 74, n.06, junho de 2010.

LIMA, Alvino. Da influência, no direito civil, do movimento socializador do direito. Revista Forense. Rio de Janeiro: Forense, out. 1939 - Apud MARQUES; MIRAGE, 2012.

MARQUES, Claudia Lima; Miragem, Bruno. O novo direito privado e a proteção dos vulneráveis. São Paulo: Revista dos Tribunais. 2012.

MARTINS, Sérgio Pinto. Direito do trabalho. 22. ed. São Paulo: Atlas. 2006.

MENDES, Gilmar Ferreira; COELHO, Inocêncio Mártires; BRANCO, Paulo Gustavo Gonet. Curso de direito constitucional. 2. ed. São Paulo: Saraiva. 2008.

NASCIMENTO, Amauri Mascaro. Curso de direito do trabalho. 20. ed. São Paulo: Saraiva. 2005.

NIESS, Luciana Toledo Távora; NIESS, Pedro Henrique Távora. Pessoas portado- 
ras de deficiência no direito brasileiro. 1. ed. São Paulo: Juarez de Oliveira. 2003.

ROTHENBURG, Walter Claudius. Direito constitucional. 1. ed. São Paulo: Verbatim. 2010.

SILVA, José Afonso da. Aplicabilidade das normas constitucionais. 8. ed. São Paulo: Malheiros. 2012. 